\title{
MORTALITY, WEIGHT LOSS AND QUALITY OF LIFE OF PATIENTS WITH MORBID OBESITY: evaluation of the surgical and medical treatment after 2 years
}

\author{
Gunther Peres PIMENTA ${ }^{1}$, Robson Tadashi SARUWATARI ${ }^{2}$, Manoela Regina Alves CORRÊA², \\ Pedro Luiz GENARO ${ }^{2}$ and José Eduardo de AGUILAR-NASCIMENTO ${ }^{3}$
}

\begin{abstract}
Context - The surgical treatment for morbid obesity is becoming common in this country. Only a few papers reported the long-term results of the surgical approach for morbid obesity, mainly in terms of quality of life. Objective - To compare mortality rate, weight loss, improvement of both diabetes and hypertension, and quality of life of patients from the public healthcare in Cuiabá, MT, Brazil, who underwent either medical or surgical interventions after a minimum of 2 years. Methods - The population of this study was constituted by morbidly obese patients who initiated treatment between June 2002 and December 2006. The casuistic consisted of 89 patients submitted to medical therapy and 76 patients who underwent surgical procedures. The main variables were weight loss, improvement of hypertension and diabetes, quality of life, and mortality. Results - The overall results showed that weight loss was significant in the two groups $(P<0.001)$; however surgical patients showed a greater loss than the medical group $(P=0.05)$. The improvement of diabetes and hypertension was significantly greater in the surgical group $(P<0.001)$, in which no cases of diabetes persisted. There was an increase in cases of hypertension among patients receiving medical attention. Mortality occurred in six cases $(6.7 \%)$ of the medical group and in five cases $(6.6 \%)$ of the surgical group $(P=0.97)$. The median grade of the quality of life score obtained by surgical patients $(2.37$ [range: -2.50 to 3.00$])$ was significantly greater $(P<0.001)$ when compared to the medical group (1.25 [range: -1.50 to 3.00]). Conclusion - The surgical group presented better results regarding the weight loss, quality of life and improvement of hypertension and diabetes. There was no significant difference in mortality rate between the two groups after a minimum of 2 years.
\end{abstract}

HEADINGS - Obesity, morbid. Mortality rate. Weight loss. Quality of life.

\section{INTRODUCTION}

Obesity is a universal disease of growing prevalence that has been acquiring alarmingly epidemic proportions, affecting more than one billion adults and being one of the main public health problems of modern society ${ }^{(32,39)}$. Obesity is a disease classified according to WHO (World Health Organization) through the body mass index (BMI). This index is obtained by dividing the weight in $\mathrm{kg}$ by the square of the height in meters ${ }^{(32)}$, and a BMI over $40 \mathrm{~kg} / \mathrm{m}^{2}$ is pronounced as morbid obesity ${ }^{(53)}$.

In the year 2000, one-third of the population of the USA was overweight or obese ${ }^{(13,36,53)}$. More than 400,000 people die every year due to complications of obesity which is along with tobacco, the two leading causes of death in that country ${ }^{(20,52)}$. The IBGE (Brazilian Institute of Geography and Statistics) census of 2004 demonstrated that $40.6 \%$ of adult Brazilian are overweight, and the state of Mato Grosso is following the trend ${ }^{(25)}$.

Excess of weight is associated with the raise of morbidity and mortality, and this risk rises progressively according to the weight gain. Obese individuals die more from diseases related to the cardiovascular system, especially stroke and acute myocardial infarction, when compared to individuals with normal weight ${ }^{(16}$, 18). Diabetes and arterial hypertension occur 2.9 times more frequently in obese individuals ${ }^{(51)}$. In Brazil, the costs of hospital admissions due to obesity and excess weight represent $3.02 \%$ for men and $5.83 \%$ for women ${ }^{(46)}$.

Department of Surgery of the Medical Sciences School, Federal University of Mato Grosso, Cuiabá, MT, Brazil.

${ }^{1}$ Postgraduate Course of the Medical Sciences School, Federal University of Mato Grosso; ${ }^{2}$ Medical School of the University of Cuiabá, MT; ${ }^{3}$ Department of Surgery, Medical Sciences School, Federal University of Mato Grosso, Cuiabá, MT, Brazil.

Correspondence: Prof. José Eduardo de Aguilar Nascimento - Rua Estevão de Mendonça, 81 - apt. 801 - 78043-300 - Cuiabá, MT, Brasil. E-mail: aguilar@terra.com.br 
The Health Ministry of Brazil recommends that obesity treatment should always start with medical measures including diet, psychotherapy, various medications, and physical exercise. This approach should be accompanied by a multidisciplinary team (endocrinologist, psychologist, psychiatrist, nutritionist, among others) for at least 2 years. If this approach fails, the option for surgical treatment exists for patients with either associated chronic diseases (BMI between 35 and $40 \mathrm{~kg} / \mathrm{m}^{2}$ ) or morbid obesity (BMI over $\left.40 \mathrm{~kg} / \mathrm{m}^{2}\right)^{(3)}$.

The medical management of obesity is difficult because both weight loss and maintenance of the achieved weight are not possible for most of the extreme obese patients. Approximately $30 \%$ to $35 \%$ of the weight loss is regained after 1 year of the initiation of the treatment in up to $50 \%$ of the patients ${ }^{(9)}$.

Surgical treatment for obesity began in the middle of the 20th century. Operations for obesity are classified into three types: restrictive, disabsorptive, and mixed ${ }^{(17,29)}$. In the USA, bariatric surgery is becoming the most common elective surgery, with 100,000 new cases each year ${ }^{(5)}$.

The negative impact of obesity is related not only to morbidity and mortality, but also to quality of life, which is defined by the WHO as "a broad-ranging concept incorporating in a complex way the person's physical health, psychological state, level of independence, social relationships, and their relationship with the salient features of their environment"(4). As there are few data regarding the treatment of morbid obesity in the state of Mato Grosso and few works contemplating the theme in Brazil (with more repercussion in the mass media than in the scientific database), we assume that there is a need for more information. Most of the existing studies compare surgical procedures among themselves and do not observe what happens in the long term with either the operated or unoperated obesity patients. Therefore, this study aimed to fill this gap in scientific information and also to compare the overcome of morbidly obese patients who underwent either medical or surgical treatment. Thus, we compare the mortality rate, weight loss, evolution of diabetes and arterial hypertension, and quality of life among morbidly obese individuals and submitted to either medical or surgical treatment for a minimum of 2 years.

\section{METHODS}

This is an observational, clinical, historical cohort study for the evaluation of therapeutic effectiveness. This work was approved by the Human Research Ethics Committee of the Júlio Müller University Hospital, Cuiabá, MT, Brazil - in May 14, 2008, protocol number 493/CEP-HUJM/08.

The study population was constituted of individuals with morbid obesity enrolled in the electronic database of the Brazilian Public Healthcare System at the State Reference Center in Medium and High Complexity (CERMAC) of the State Health Secretariat, and those enrolled in the electronic system of the Cuiabá University General Hospital and the Júlio Muller University Hospital of the Federal University of Mato Grosso, from June 2002 to December 2006.
It was programmed to contact all the patients by telephone and invite them to either return to the outpatient department or to receive the researchers in their homes, where the protocol for data collection would be filled.

\section{Inclusion and exclusion criteria}

Elegility for the study included patients with ages between 18 and 55 years old, from both sexes, with an initial BMI equal to superior than $40 \mathrm{~kg} / \mathrm{m}^{2}$, and with at least 2 years of ongoing clinical or surgical treatment. The exclusion criteria included patients who were not found or have refused to participate in the study.

\section{Main outcome variables}

The main outcome variables were mortality during the period of the study, quantity of weight loss, and quality of life. Secondly, we looked at the improvement of both arterial hypertension and diabetes mellitus, defined as complete interruption of the medications by order of the physician. The weight, height, and BMI information was collected during the evaluations.

\section{Study groups}

The patients were divided into two groups in order to compare the main outcome variables: group 1 - patients submitted to surgical treatment; and group 2 - patients submitted to medical treatment. The following operations were performed: the Fobi-Capella procedure ${ }^{(10)}$ or the duodenal switch procedure ${ }^{(24)}$. The type of operation was at the surgeon's discretion. The two procedures were performed as classically described.

Patients followed the Health Ministry protocol ${ }^{(3)}$ under the supervision of medical team at CERMAC, and were only operated on when medical treatment failed. Basically medical treatment included nutritional care, drugs as ansiolitics, anorexigens, anti-depressives, etc as appropriated and at the physician's discretion. The surgical indication protocol consists of the following: patient suffering from morbid obesity for more than 2 years, with a BMI higher than $40 \mathrm{~kg} / \mathrm{m}^{2}$, and a failure of the conservative treatment (diet, psychotherapy, medication, and physical exercise) performed continually for at least 2 years.

\section{Quality of life questionnaire}

Patients filled out the Moorehead-Ardelt Quality of Life Questionnaire $^{(40,41)}$ during the interview. This questionnaire consists of five questions regarding self-esteem, disposition for physical activities, social life, disposition for work, and sexual activity. Patients that died during the study were removed from the analysis. Each of the five quality of life questions had five possible answers that generate a final value for each question (Figure 1). The sum of the values attributed to each of the five questions resulted in the individual value of each case, varying from -3 (lowest quality of life) to +3 (highest quality of life). After this, the final values of the questionnaire were categorized into five quality of life classes: very poor, poor, fair or no alteration, good and very good (Table 1 ). 


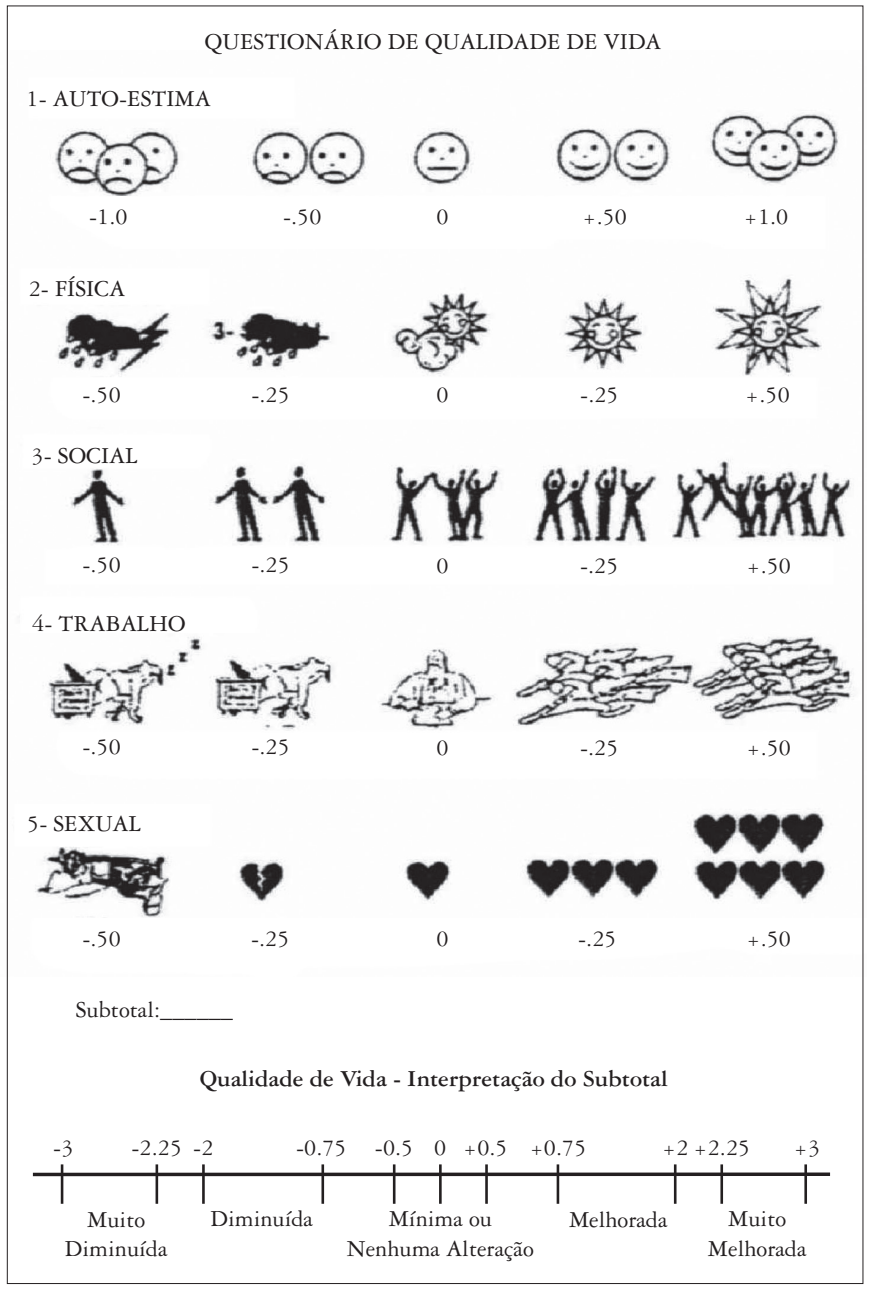

FIGURE 1. Score of the Moorehead-Ardelt for quality of life

TABLE 1. Quality of life classification according to the score obtained in the Moorehead-Ardelt Questionnaire

\begin{tabular}{ll}
\hline Quality of life classification & Score interval \\
\hline Very poor & 3.00 to 2.25 \\
Poor & 2.00 to -0.75 \\
Fair or no alteration & -0.50 to +0.50 \\
Good & 0.75 to 2.00 \\
Very good & 2.25 to 3.00 \\
\hline
\end{tabular}

\section{Statistical analysis}

Statistical analyses were performed in the program Statistical Package for the Social Sciences (SPSS-8.0). Continous data were compared using of repeated measures analysis of variance (before and after treatment). Chi-square test or Fischer test was used to compare categoric variables. A $5 \%(P<0,05)$ significance level was adopted.

\section{RESULTS}

\section{Descriptive analysis}

A total of 769 patients were elegible through the electronic systems of the three databases, being $621(80.7 \%)$ from CERMAC, $129(16.8 \%)$ operated on at Cuiabá University General Hospital, and $19(2.5 \%)$ operated on at Júlio Muller University Hospital. A total of 604 were excluded (551 in medical therapy and 53 in surgical treatment) due to the following causes: 8 patients $(1 \%)$ refuse to participate of the study and other $596(77.5 \%)$ were not found. Therefore, 165 patients entered the study distributed into two groups: a) group 1:89 patients that underwent medical treatment; and b) group 2: 76 patients submitted to surgical treatment.

Sixty-eight patients were operated on at Cuiabá University General Hospital and 8 at the Júlio Muller University Hospital. Thirty-two (42.1\%) patients received a gastric bypass (FobiCapella technique $)^{(9)}$ and $44(57.9 \%)$ underwent a biliopancreatic diversion (Duodenal Switch: Hess and Marceau technique) ${ }^{(24,33)}$.

Demographic data and clinical variables of the patients included in both groups of the study can be seen in Table 2 .

TABLE 2. Demographic and clinical variables in the two groups $(n=165)$

\begin{tabular}{lccc}
\hline & $\begin{array}{c}\text { Surgical } \\
\mathrm{n}=76\end{array}$ & $\begin{array}{c}\text { Clinical } \\
\mathrm{n}=89\end{array}$ & $P$ \\
\hline Sex (M/F) & $15 / 61$ & $7 / 82$ & 0.02 \\
Age (years) & $38.4 \pm 8.2$ & $40.4 \pm 9.4$ & 0.14 \\
Weight (kg) & $133.6 \pm 21.2$ & $117.3 \pm 21.9$ & $<0.001$ \\
BMI (kg/m²) & $49.4 \pm 6.6$ & $45.3 \pm 6.1$ & $<0.001$ \\
Follow-up (months) & $43.2 \pm 5$ & $33.3 \pm 8.5$ & $<0.001$ \\
Diabetes & $12 / 61(19.7 \%)$ & $10 / 63(15.9 \%)$ & 0.19 \\
Hypertension* & $30 / 61(49.2 \%)$ & $34 / 63(54 \%)$ & 0.59 \\
\hline *Den: 124 mrienss & & &
\end{tabular}

There was no difference between the two groups regarding age, incidence of hypertension and diabetes. However, the severity of obesity quantified by both weight and BMI was significantly higher in the surgical patients. Likewise, the average follow-up in the surgical group was approximately 10 months longer than in the medical group. Finally, the number of male patients in the surgical group was significantly higher.

\section{Weight}

A significant weight loss $(P<0.001)$ was observed in both treatment groups. However, the operated group presented significantly higher weight loss than the medical group $(P=0.05)($ Table 3$)$. 
TABLE 3. Evolution of weight, BMI, diabetes and systemic arterial hypertension in the two groups

\begin{tabular}{cccc}
\hline & Surgical & Clinical & $\begin{array}{c}P \\
\text { Inter-groups }\end{array}$ \\
\hline Weight $(\mathrm{kg})($ mean $\pm \mathrm{SD})$ & & \\
Before & $133.6 \pm 21.2$ & $117.3 \pm 21.9$ & 0.05 \\
After & $81.9 \pm 18.9 \mathrm{a}$ & $110.9 \pm 25.9 \mathrm{a}$ & \\
BMI $\left(\mathrm{kg} / \mathrm{m}^{2}\right)($ mean $\pm \mathrm{SD})$ & & \\
Before & $49.4 \pm 6.6$ & $45.3 \pm 6.1$ & $<0.001$ \\
After & $30.2 \pm 6.3^{\mathrm{a}}$ & $42.6 \pm 8.0^{\mathrm{a}}$ & \\
Diabetes (n, \%) & & & $<0.001$ \\
Before & $12 / 61(19.7)$ & $10 / 63(15.9)$ & \\
After & $0 / 61(0.0)^{\mathrm{a}}$ & $5 / 63(8.2)$ & $<0.001$ \\
Hypertension $(\mathrm{n}, \%)$ & & & \\
Before & $30 / 61(49.2)$ & $34 / 63(54)$ & \\
After & $7 / 61(11.5)^{\mathrm{a}}$ & $40 / 63(63.5)$ & \\
\hline $\mathrm{a}=P<0.001$ versus before & & &
\end{tabular}

\section{Body mass index}

In consonance with weight loss, BMI significantly decreased $(P<0.001)$ in the two types of treatment, though it was significantly more expressive $(P<0.001)$ in the surgical group (Table 3 ). Mean BMI of the medical group remained higher than $40 \mathrm{~kg} / \mathrm{m}^{2}$

\section{Diabetes}

A significant improvement of the diabetes was observed only in the surgical group after the treatment $(P<0.001)$. All patients improved and no cases of diabetes existed in the follow-up $(P<0.001)$. On the other hand, no difference was observed during evolution in the medical treatment group $(P=0.17)$ (Table 3).

\section{Hypertension}

During follow-up the percentage of patients with hypertension fell significantly in the surgical group, whereas a high number of patients with hypertension was still observed in the medical group $(P=0.28)$ (Table 3$)$.

\section{Mortality}

Eleven patients $(6.6 \%)$ died during follow-up: $6(6.7 \%)$ in the medical group and $5(6.6 \%)$ in the surgical group $(P=$ $0.97)$. All six medical patients died in consequence of various cardiovascular diseases. Surgical patients died due to either early (two) or late (three) postoperative complications.

\section{Quality of life}

The average score obtained by the surgical patients (median $=2.37$ [range -2.50 to 3.00$])$ was significantly higher $(P<0.001)$ than the average score obtained by the medical group (median $=1.25$ [range -1.50 to 3.00]) (Figure 2). Approximately 93\% of the surgical patients presented an improvement in quality of life, contrasting with only $65.4 \%$ of the medical patients $(P<0.001)$, as can be observed in Table 4 . There was no difference in quality of life between the two surgical procedures.

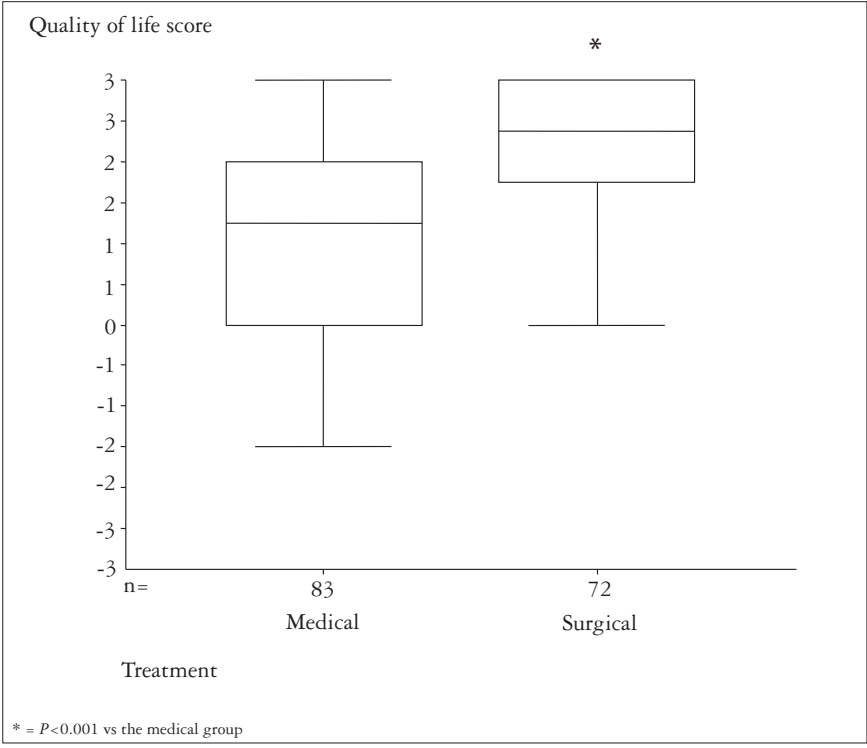

FIGURE 2. Score of the Moorehead-Ardelt for quality of life in the two groups. Data express the median, the interquartile range and variation.

TABLE 4. Patient distribution according to the quality after treatment in the two study groups

\begin{tabular}{lcc}
\hline & Surgical $(\mathrm{n}, \%)$ & Clinical $(\mathrm{n}, \%)$ \\
\hline Very poor & $1(1.4)$ & \\
Poor & $1 *(1.4)$ & $8(9.6)$ \\
Fair or no alteration & $3 *(4.2)$ & $24(28.9)$ \\
Good & $26(36.6)$ & $36(43.4)$ \\
Very good & $40 *(56.3)$ & $15(18.1)$ \\
Total $\dagger$ & $71(100 \%)$ & $83(100 \%)$ \\
\hline
\end{tabular}

$=P<0,001$ versus the same category in the medical treatment

$\dagger=$ data refers to 154 patients (11 died and were not computed)

\section{DISCUSSION}

Our data showed that surgical treatment was associated with significantly more benefits in both clinical and nutritional parameters, and in the quality of life of the patients. A more expressive loss of weight was observed in the surgical group, as well as a significant improvement of diabetes and hypertension. Furthermore, the quality of life observed after 2 or more years of follow-up was higher among the patients submitted to bariatric surgery.

Endpoints such as weight loss, improvement of diabetes and hypertension, mortality, and quality of life were chosen in this study because they are easy to obtain and can reflect either clinical improvement or worsening of the patients. Furthermore, these parameters serve as guidelines for the Public Healthcare System (SUS) regarding the effectiveness of the proposed treatments.

Most studied patients were females, suggesting that women present a higher prevalence of obesity ${ }^{(25)}$, or that they are more willing to seek obesity treatment. In opposition, men are most prone to a definitive treatment and thus, this may explain the larger number of male surgical patients in 
our study. For women, the desire to improve their physical appearance, to reduce discontentment with their body, and to cease discrimination seem to constitute the main motivations for changing body size and shape ${ }^{(2)}$.

The most frequent age group was 30-45 years, confirming many other works ${ }^{(12,24)}$. The average follow-up time was longer in the surgical group when compared to the medical group $(P<0.001)$, suggesting the greater concern of the surgical patients during follow-up. All patients presented a BMI equal to or greater than $40 \mathrm{~kg} / \mathrm{m}^{2}$ in the beginning of the treatment, and even though the surgical group was heavier than the medical group, it experienced a more pronounced weight loss $(P<0.001)$.

Among the operations, literature shows that disabsorptive procedures (Scopinaro and duodenal switch) present better results in weight loss and weight maintenance when compared to the gastric bypass (Fobi-Capella) ${ }^{(38,49)}$. Loss of excess weight 12 months after the duodenal switch stays around $70 \%$ to $80 \%{ }^{(6)}$, with a minimum weight loss of $30 \%{ }^{(19,27)}$. The meta-analysis performed by Buchwald et al. ${ }^{(6)}$ demonstrated that 1 year after the postoperative period, average weight loss was similar in the two employed procedures, and that this loss was maintained up to 4 years later.

Clinical treatment of morbid obesity through supervised diets combined with psychological therapy and exercise programs should be the first line of treatment, but results are disappointing ${ }^{(9)}$. Medical treatment associated with physical activity presented a weight loss of $5 \%$ to $10 \%$ in a 4 to 6-months follow-up ${ }^{(50)}$. Among the successful patients, only $5 \%$ to $10 \%$ are able to maintain the results for more than 2 years ${ }^{(54)}$. Our findings showed that medical treatment presented unsatisfactory results, because BMI remained high and in the degree of morbid obesity.

Bariatric surgery may favor the obese patient in other aspects besides of weight loss alone. The meta-analysis performed by Mummadi et al. ${ }^{(37)}$ showed that improvement or cure of steatosis and steatohepatitis occured after weight loss with bariatric surgery. In a similar fashion, the meta-analysis of Greenburg et al. ${ }^{(21)}$ showed a significant improvement of sleep apnea. Furthermore, Christou et al. ${ }^{(11)}$ associated bariatric surgery to reduced cardiovascular risk, appearance of tumors, endocrine alterations, infections, and psychiatric disorders

Diabetes and hypertension possess a direct relationship with obesity. Central obesity explains the higher risk of type II diabetes ${ }^{(23)}$. According to the meta-analysis of Buchwald et al. ${ }^{(8)}$, Scopinaro, duodenal switch, and Capella procedures may cure diabetes in $78.1 \%$ of the cases and may clinical improve the disease in $86.6 \%$ of them. Long et al. ${ }^{(30)}$ observed a 30 times lower relative risk of developing type II diabetes mellitus in operated morbidly obese patients than in unoperated patients

The incidence of arterial hypertension in our study also dropped in the operated patients, contrasting with a rise in the clinically treated patients. Small weight changes after surgical treatment are considered enough to provide improvement in comorbidities ${ }^{(42,47,48)}$. A weight loss of $10 \mathrm{~kg}$ already offers benefits regarding control of systemic arterial hypertension, angina, diabetes and lipid profile $^{(47)}$ One meta-analysis showed that $76.8 \%$ and $61.7 \%$ of patients submitted to bariatric surgery had resolution of diabetes and hypertension respectively ${ }^{(6)}$. This is very similar to our findings.

Postoperative complications are feared in bariatric surgeries, and mortality rate after bariatric surgery can reach $7 \%{ }^{(34,45)}$. However, in experienced centers, anastomotic dehiscences are found at a rate of $1 \%{ }^{(35)}$. Centers of excellence in bariatric surgery report hospital mortality rates between $0.14 \%$ and $0.29 \%$ up to the 30 th postoperative day ${ }^{(43)}$. Fandiño et al. ${ }^{(15)}$ describe that postoperative mortality figures between $0.3 \%$ and $1.6 \%$. The Capella procedure presents an immediate postoperative mortality rate of $1 \%$ and late postoperative mortality rate of $1.1 \%{ }^{(31)}$, while the rate for duodenal switch is $0.57 \%{ }^{(7)}$. The meta-analyses of Maggard et al ${ }^{\left({ }^{31}\right)}$ and Buchwald et al ${ }^{(8)}$ report the mortality rate of bariatric surgery as lower than $1 \%$. However, after promoting weight loss, bariatric surgeries reduce mortality rates in the long term ${ }^{(1,35)}$. In the literature, most studies have made comparisons of mortality between surgical procedures ${ }^{(7,31)}$. In this context, the literature is deficient in studies that compare mortality after medical and surgical obesity treatments. Schernthaner et al. ${ }^{(44)}$ reinforce the evidence of excess weight as a risk factor for premature mortality. A weight reduction of $10 \mathrm{~kg}$ promotes a $20 \%$ to $25 \%$ reduction in general mortality, with $30 \%$ to $40 \%$ of the deaths being diabetes-related ${ }^{(26)}$. In our study, there was no significant statistical difference in mortality between patients submitted to surgical rather than medical treatment.

Surgical patients presented a quantitative improvement in quality of life compared to the clinical group, as reported earlier ${ }^{(28)}$. It is curious to understand why an improvement in quality of life occurred in the medical patients, despite no significant improvement of obesity and diabetes and a rise in the number of hypertension cases? We assume that probably occurred due to outpatient assistance offered by the multidisciplinary team of the CERMAC.

There are many questionnaires published in the literature that evaluate the quality of life of bariatric patients ${ }^{(14,22,41)}$. The Moorehead-Ardelt Questionnaire is currently considered the best and is the most used instrument for comparing different operation techniques of different surgeons. However, the questionnaire is criticized by many authors for presenting results based on subjective data and for not presenting questions that evaluate the feeding behavior of the operated patients ${ }^{(22,41)}$.

Our study presented a few deficiencies, such as the limitations of the quality of life questionnaire and the lack of laboratory data regarding the medical improvement of diabetes. Another deficiency is the fact that this study is not prospective or randomized. It is a historical cohort that has potential flaws, such as the large number of cases not found, the chance for a more accentuated improvement in the clinical group with a longer follow-up, and the bias of selecting patients with the best conditions for the surgical group. Nevertheless, all of this seems unlikely, because the surgical group was in 
fact heavier and the proportion of comorbidities was similar. The absence of a longer follow-up is probably due to a noncontinuity of the clinical treatment by many patients who did not observe any improvement. New studies and alternative approaches, preferably prospective studies, are needed to address this problem.

\section{CONCLUSION}

Surgical approach to morbid obese patients are most effective than traditional management. Not only weight loss is most significative but improvement of comorbidities such as diabetes and hypertension is higher.

Pimenta GP, Saruwatari RT, Corrêa MRA, Genaro PL, Aguilar-Nascimento JE. Mortalidade, perda de peso e qualidade de vida em pacientes com obesidade mórbida: avaliação do tratamento cirúrgico e clínico após 2 anos. Arq Gastroenterol. 2010;47(3):263-9.

RESUMO - Contexto - O tratamento cirúrgico da obesidade mórbida, vem se tornando frequente no país. Poucos trabalhos avaliaram os resultados a longo prazo do tratamento cirúrgico da obesidade mórbida, principalmente em termos de qualidade de vida. Objetivo - Comparar pacientes usuários do SUS em Cuiabá, MT tratados clínica ou cirurgicamente, observando taxa de mortalidade, perda de peso, evolução do diabetes e hipertensão e qualidade de vida após pelo menos 2 anos do início do tratamento. Método - A população do estudo foi constituída de obesos mórbidos pacientes da rede pública, tratados no período de junho de 2002 a dezembro de 2006. A casuística consistiu de 89 pacientes tratados clinicamente e 76 pacientes operados. As principais variáveis foram perda de peso, melhora da hipertensão e diabetes, qualidade de vida e mortalidade. Resultados - Houve significativa perda de peso nos dois grupos $(P<0.001)$, porém pacientes operados apresentaram queda significativamente maior do que o grupo clínico $(P=0,05)$. Diabetes e hipertensão apresentaram melhora significativa apenas no grupo cirúrgico $(P<0,001)$, não se evidenciando mais casos de diabetes entre eles e havendo aumento do número de hipertensos entre os tratados clinicamente. A mortalidade após 2 anos foi de seis casos (6,7\%) no grupo clínico e de cinco $(6,6 \%)$ no cirúrgico $(P=0,97)$. A média da pontuação de qualidade de vida obtida pelos pacientes cirúrgicos $(2,37$ [variação: $-2,50$ a 3,00]) foi significativamente maior $(P<0,001)$ que a obtida pelo grupo clínico ( 1,25 [variação: $-1,50$ a 3,00$])$. Conclusão - O grupo cirúrgico apresentou melhores resultados quanto à perda de peso, qualidade de vida e melhora da hipertensão e diabetes. Não houve diferença estatisticamente significante quanto a taxa de mortalidade quando comparados pacientes submetidos aos dois tipos de tratamento.

DESCRITORES - Obesidade mórbida. Coeficiente de mortalidade. Perda de peso. Qualidade de vida.

\section{REFERENCES}

1. Adams TD, Gress RE, Smith SC, Halverson RC, Simper SC, Rosamond WD, Lamonte MJ, Stroup AM, Hunt SC. Long-term mortality after gastric bypass surgery. N Engl J Med 2007;357:753-61.

2. Almeida GAN, Santos JE, Pasin SR, Loureiro SR. Percepção de tamanho e forma corporal de mulheres: estudo exploratório. Psicologia em Estudo. 2005;10:27-35.

3. Brasil. Ministério da Saúde. Portaria n ${ }^{\circ} 196$, de 29 de fevereiro de 2000. Aprova os critérios clínicos para a indicação de realização da gastroplastia como tratamento cirúrgico da obesidade mórbida, no âmbito do Sistema Único de Saúde. Diário Oficial da União, Brasília (DF). 20001 mar.

4. Brow J, Macgee HM, O'Boyle CA. Conceptual approaches to the assessment of quality of life. Phychology Health. 1997;12:737-51.

5. Buchwald H, Williams SE. Bariatric surgery worldwide 2003. Obes Surg. 2004; 14:1157-64

6. Buchwald H, Avidor Y, Braunwald E, Jensen MD, Pories W, Fahrbach K, Schoelles K. Bariatric surgery. A systematic review and meta-analysis. JAMA. 2004;292:1724-37.

7. Buchwald H, Estok R, Fahrbach K, Banel D, Sledge I. Trends in mortality in bariatric surgery: a systematic review and meta-analysis. Surgery. 2007;142:621-32.

8. Buchwald H, Estok R, Fahrbach K, Banel D, Jensen MD, Pories WJ, Bantle JP, Sledge I. Weight and type 2 diabetes after bariatric surgery: systematic review and meta-analysis. Am J Med. 2009;122:248-56.

9. Cabral MD. Tratamento clínico da obesidade. In: Garrido Jr AB, editor. Cirurgia da obesidade. São Paulo: Atheneu; 2002. p.35-44.

10. Capella RF, Capella JF, Mandac H. Vertical banded gastroplasty - gastric bypass: preliminary report. Obes Surg. 1991;1:389-96.

11. Christou NV, Sampalis JS, Liberman M, Look D, Auger S, McLean AP, McLean LD. Surgery decreases long-term mortality, morbidity and health care use in morbidity obese patients. Ann Surg. 2004;240:416-24.

12. Ciovica R, Takata M, Vittinghoff E, Lin F, Posselt M, Rabl C, Stein HJ, Campos GM. The impact of roux limb length on weigth loss after gastric bypass. Obes Surg. 2008;18:5-10.

13. Deitel M. Overweight and obesity worldwide now estimated to involve 1,7 billion people. Obes Surg. 2003;13:329-30.
14. Duval K, Marceau P, Pérusse L, Lacasse Y. An overview of obesity-specific quality of life questionnaires. Obes Rev. 2006;7:347-60.

15. Fandiño J, Benchimol AK, Coutinho WF, Appolinário JC. Cirurgia bariátrica: aspectos clínoc-ciréugicos e psiquiátricos. Rev Psiquiatr Rio Gd Sul. 2004; 26:47-51.

16. Federación Latinoamericana de Sociedades Obesidad (FLASO). I Consenso Latino-americano em obesidade. Rio de Janeiro; 1998.

17. Fobi MAL, Lee H, Flemming A. The surgical technique of the banded Roux-in-Y gastric bypass. J Obesity Weight Reg. 1989;8:99-102.

18. Francischi RPP, Preira LO, Freitas CS, Klopfer M, Santos RC, Vieira P, Lancha $\mathrm{Jr}$ AH. Obesity: updated information about its etiology, morbidity and treatment. Rev Nutr. 2000;13:17-28.

19. Gagner M, Matteotti R. Laparoscopic biliopancreatic diversion with duodenal switch. Surg Clin North Am. 2005;85:141-9.

20. Gong K, Gagner M, Pomp A, Almahmeed T, Bardaro SJ. Micronutrients deficiencies after laparoscopic gastric bypass: recommendations. Obes Surg. 2008;18:1062-6.

21. Greenburg DL, Lettieri CJ, Eliasson AH. Effect of surgical weigth loss on measures of obstructive sleep apnea: a meta-analysis. Am J Med. 2009;122:535-42.

22. Guyatt GH, Feeny DH, Patrick D. Measuring health-related quality of life. Ann Intern Med. 1993;118:622-9.

23. Harte AL, MacTernan PG, MacTernan CL, Crocker J, Starcynski J, Barnett AH, Matyka K, Kumar S. Insulin increases angiotensinogen expression in human abdominal subcutaneous adipocytes. Diabetes Obes Metab. 2003;5:462-7.

24. Hess DS, Hess DW. Biliopancreatic diversion with a duodenal switch. Obes Surg. 1998;8:267-82.

25. IBGE. Pesquisa de orçamentos familiares 2002-2003. [acesso em 2008 Maio 3]. Disponível em: http://www.ibge.gov.br/.

26. Jung RT. Obesity as a disease. Br Med Bull. 1997;53:307-21.

27. Kim WW, Gagner M, Kini S, Inabnet WB, Quinn T, Herron D, Pomp A. Laparoscopic vs open biliopancreatic diversion with duodenal switch: a comparative study. J Gastrointest Surg. 2003;7:552-7.

28. Kolotkin RL, Crosby RD, Gress RE, Hunt SC, Adams TD. Two-years changes in helth-related quality of life in gastric bypass compared with severely obese controls. Surg Obes Relat Dis. 2009;5:250-6.

29. Kremen AJ, Linner JH, Nelson CH. An experimental evaluation of the nutritional importance of proximal and distal small intestine. Ann Surg. 1954;140:439-48. 
30. Long SD, O’Brien K, MacDonald KG Jr, Leggett-Frazier N, Swanson MS, Pories WJ, Caro JF. Weight loss in severely obese subjects prevents the progression of impaired glucose tolerance to type II diabetes. A longitudinal interventional study. Diabetes Care. 1994;17:372-5.

31. Maggard MA, Shugarman LR, Suttorp M, Maglione M, Sugerman HJ, Livingston EH, Nguyen NT, Li Z, Mojica WA, Hilton L, Rhodes S, Morton SC, Shekelle PG. Meta-analysis: surgical treatment of obesity. Ann Intern Med. 2005;142:547-59.

32. Mancini HC. Noções fundamentais - Diagnóstico e classificação da obesidade. In: Garrido Jr AB, editor. Cirurgia da obesidade. São Paulo: Atheneu; 2002. p.1-7.

33. Marceau P, Hould FS, Simard S, Lebel S, Bourque RA, Potvin M, Biron S. Biliopancreatic diversion with duodenal switch. World J Surg. 1998;22:947-54.

34. Mason EE, Tang S, Renquist KE, Barnes DT, Cullen JJ, Doherty C, Maher JW. A decade of change in obesity surgery. Obes Surg. 1997:7:189-97.

35. Miller K, Hell E. Malabsorptionsmethoden in der bariatrischen Chirurgie. Zentralbl Chir. 2002;127:1044-8

36. Mong C, Van Dam J, Morton J, Curet M, Banerjee S. Preoperative endoscopic screening for laparoscopic Roux-en-Y gastric bypass has a low yield for anatomic findings. Obes Surg. 2008;18:1067-73.

37. Mummadi RR, Kasturi KS, Chennareddygari S, Sood GK. Effect of bariatric surgery on nonalcoholic fatty liver disease: systematic review and meta-analysis. Clin Gastroenterol Hepatol. 2008;6:1396-402.

38. Nicareta JR. Comparação de cinco técnicas para o tratamento cirúrgico da obesidade mórbida com o BAROS - Bariatric analysis and reporting outcome system [dissertação]. Curitiba: Universidade Federal do Paraná; 2005.

39. OPAS - Organização Pan-Americana da Saúde. Doenças crônico-degenerativas e obesidade: estratégia mundial sobre alimentação saudável, atividade física e saúde. Brasília, 2003

40. Oria HE. Reporting results in obesity surgery: evaluation of limited survey. Obes Surg. 1996;6:361-8.

41. Oria HE, Moorehead MK. Bariatric analysis and reporting outcome system (BAROS). Obes Surg. 1998;8:487-99.

42. Palazuelos-Genis T, Mosti M, Sánchez-Leenheer S, Hernández R, Garduño O, Herrera MF. Weight loss and body composition during the first postoperative year of a laparoscopic Roux-en-y gastric bypass. Obes Surg. 2008;18:1-4.
43. Pratt GM, Mclees B, Pories WJ. The ASBS bariatric surgery centers of excellence program: a blueprint for quality improvement. Surg Obes Relat Dis. 2006;2:497-503.

44. Schernthaner G, Morton JM. Bariatric surgery in patients with morbi obesity and type 2 diabetes. Diabetes Care. 2008;31:s297-302.

45. Scopinaro N, Marinari GM, Camerini G. Laparoscopic standard biliopancreatic diversion: technique and preliminary results. Obes Surg. 2002;12:362-5.

46. Sichieri R, Nascimento S, Coutinho W. The burden of hospitalization due to overweight and obesity in Brazil. Cad Saúde Pública. 2007;23:1721-7.

47. Sjöström L, Lindroos AK, Peltonen M, Torgerson J, Bouchard C, Carlsson B1, Dahlgren S, Larsson B, Narbro K, Sjõström CD, Sullivan M, Wedwl H. Lifestyle, diabetes and cardiovascular risk factors 10 years after bariatric surgery. $\mathrm{N}$ Engl $\mathrm{J}$ Med. 2004;351:2683-93.

48. Sjöström L, Narbro K, Sjostrom CD, Karason K, Larsson B, Wedel H, Lystig T, Sullivan M, Bouchard C, Carlsson B, Bengtsson C, Dahlgren S, Gummesson A Jacobson P, Karlsson J, Lindroos AK, Lõnroth H, Nãslund I, Olbers T, Stenlõf K, Torgerson J, Agren G, Carlsson LM. Effects of bariatric surgery on mortality in Swedish obese subjects. N Engl J Med. 2007;357:741-52.

49. Strain GW, Gagner M, Inabnet WB, Dakin G, Pomp A. Comparison of effects of gastric bypass and biliopancreatic diversion with duodenal switch on weight loss and body composition 1-2 years after surgery. Surg Obes Relat Dis. 2007;3:31-6.

50. Wadden TA, Foster GD. Behavioral treatment of obesity. Med Clin North Am. 2000;84:441-61.

51. Waitzberg DL. Nutrição oral, enteral e parenteral na prática clínica. $3^{\mathrm{a}}$ ed. São Paulo: Atheneu; 2000.

52. Wax JR, Cartin A, Wollf R, Lepich S, Pinette MG, Blackstone J. Pregnancy following gastric bypass surgery for morbid obesity: maternal and neonatal outcomes. Obes Surg. 2008;18:540-4.

53. World Health Organization (WHO). Report of a WHO consultation on obesity. In: Obesity - preventing and managing the global epidemic. Geneva: WHO; 2000 265p. [acesso em 2004 Mar 01];894. Disponível em: http://apps.who.int/bookorders/ anglais/detart1.jsp?sesslan=1\&codlan=1\&codcol $=10 \& \operatorname{cod} c \mathrm{ch}=894$.

54. Zilberstein B, Galvão-Neto M, Ramos AC. O papel da cirurgia no tratamento da obesidade. Rev Bras Med. 2002;59:258-264.

Received 13/10/2009 Accepted 26/2/2010 